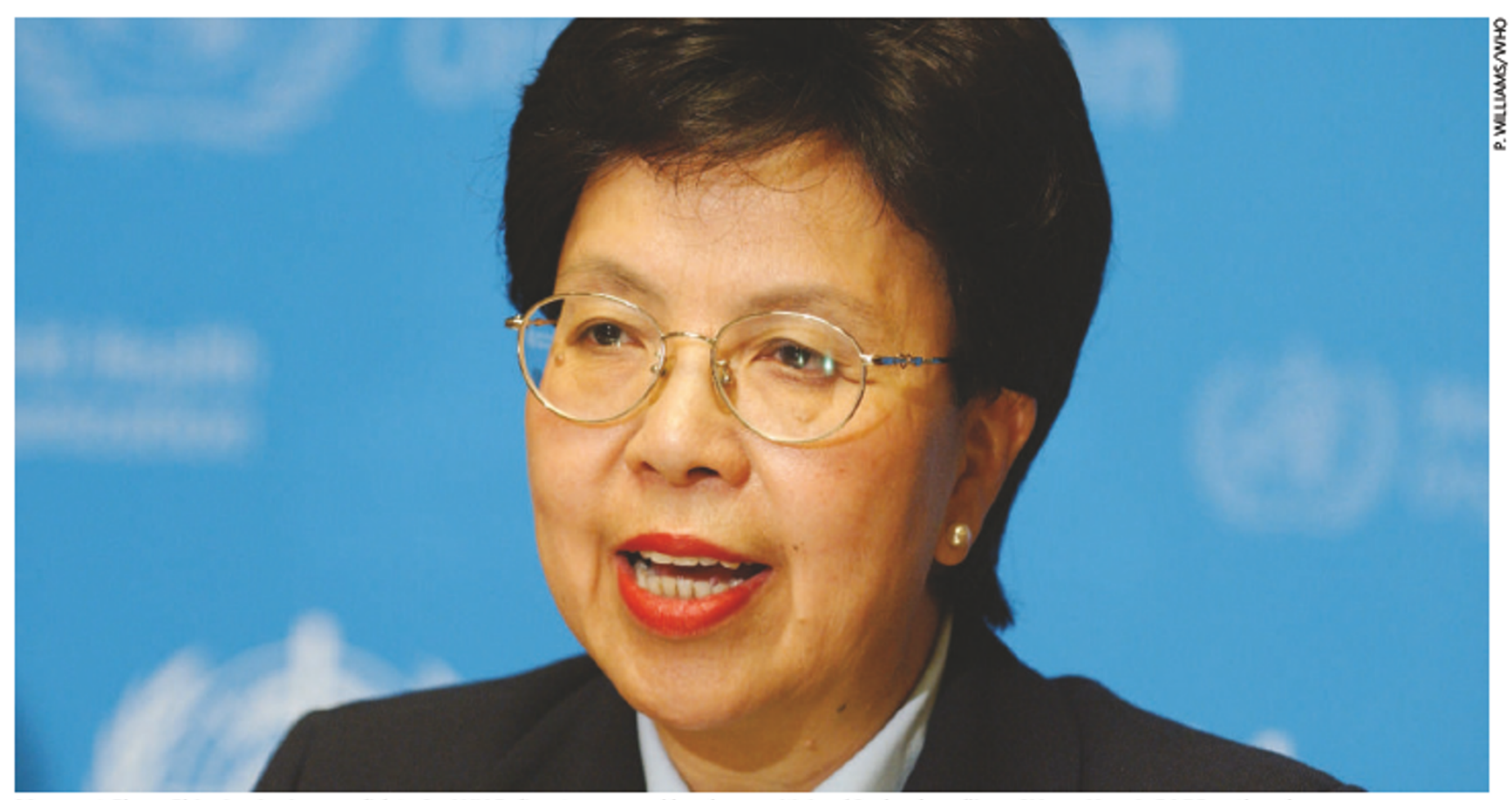

Margaret Chan: China's winning candidate for WHO director-general has been criticized for her handling of Hong Kong's SARS outbreak.

\title{
WHO boss faces test of independence
}

China has covered up outbreaks of SARS and avian influenza, and baulked at sharing samples and data with the international community. But last week, China's candidate for director-general of the World Health Organization (WHO), Margaret Chan, won a landslide victory in the election to replace South Korea's Lee Jong-wook, who died in May.

Chan's election might herald greater Chinese openness and involvement in global health. Many are watching to see if, on taking office in January, she is as independent of her sponsors as she has promised. She has made women and Africa her priorities.

The WHO faces a crisis of identity and purpose. The organization used to be the only global-health show in town, but the past decade has seen a series of new players emerge. The Global Fund to Fight AIDS, Tuberculosis and Malaria has a bigger budget than the WHO's US $\$ 1.7$ billion, and the Bill \& Melinda Gates Foundation spent almost \$1 billion last year supporting global health. And nearly 100 public-private health partnerships have sprung up, for example to develop drugs and vaccines for malaria and leishmaniasis.

In fact, the presence of more organizations spending more money gives the $\mathrm{WHO}$ a chance to reinvent itself. For all its bureaucratic rigidity, it remains the only agency plugged into health ministries worldwide, with staff in almost every country, and the capacity to bring together the world's top scientists to tackle a particular problem. In principle, it is wellplaced to help integrate the newer initiatives.

In her manifesto, Chan endorsed such a shift in the WHO's focus. She is also apparently open to change: she recently led a review panel that concluded that the Tropical Disease Research programme sponsored by the WHO, the United Nations and the World Bank needs to be rethought. Yet Chan's victory surprised even some of her colleagues, who say that her track record, latterly with the WHO's programmes on communicable diseases and pandemic influenza, is more as a diplomat than a leader.

"She is untested on the technical and political side," says Richard Horton, editor of The Lancet, which backed another candidate. "One of her first tests will be who she brings in: she needs a team that fills the gaps in her own experience."

On the eve of the election, China hosted a summit of African heads of state, and announced more than US $\$ 10$ billion in aid for trade, health and agricultural development. Besides China, the United States backed her bid. Her 12 rivals included Bernard Kouchner, former French health minister and founder of Médecins Sans Frontières.

Chan campaigned on her "outstanding leadership" as director of health in Hong Kong during the $\mathrm{H} 5 \mathrm{~N} 1$ avian flu outbreaks in 1997 and the 2003 SARS outbreak. But in 2004, a Hong Kong government inquiry sanctioned Chan for "unsatisfactory performance" in her handling of the SARS outbreak. And Hong Kong's cull of all chickens in late 1997 to stop the spread of $\mathrm{H} 5 \mathrm{~N} 1$ happened seven months after the first human $\mathrm{H} 5 \mathrm{~N} 1$ cases were reported.

Most observers are giving Chan the benefit of the doubt. "She has travelled the rocky road of H5N1 and SARS and is well equipped to head the WHO in the many challenges and opportunities that lie ahead," says Ken Shortridge, a veteran of infectious-disease research in China, now retired in New Zealand.

For Ellen t'Hoen, who leads Médecins Sans Frontières' campaign for access to essential medicines, Chan's priority must be to put health above national and business interests. For months, under US pressure, the WHOhas sat on an advisory document on using trade rules to negotiate cheaper drugs. Chan would demonstrate her independence by publishing the document, says t'Hoen.

Declan Butler 